\title{
JOURNAL.RU
}

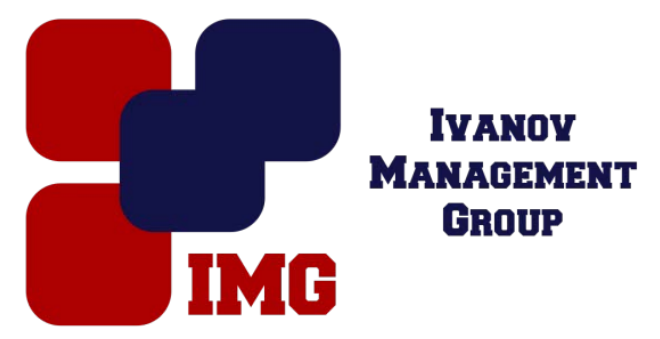

${ }^{1}$ Давыдовский Ф.Н., ${ }^{2}$ Величко Е.А. ${ }^{1}$ AНО ВО «Северо-западный открытый технический университет» ${ }^{2}$ ФГБОУ ВО«Санкт - Петербургский государственный университет.

${ }^{2}$ Колледж физической культуры и спорта, экономики и технологии»

Санкт-Петербург, Россия

doi: 10.18411/lj-30-11-2016-1-04

idsp 000001:lj-30-11-2016-1-04

\section{Структура трудовых компетенций инженеров в условиях перехода к оценке деятельностиконструкторского бюропо ключевым показателям эффективноститруда}

\footnotetext{
Аннотация

В статье рассматриваютсяметодические вопросы построения структуры трудовых компетенций инженеровна основеключевых навыков профессиональной деятельности, присущих той или иной должностной позиции, и определяющих характер и содержание труда как предмет оценки его результативности по соответствующим показателям.

Ключевые слова: трудовые компетенции, трудовые навыки, ключевые показатели эффективности труда, многозадачность, универсализм и специализация труда

\section{Abstract}

The article discusses the methodological issues of constructing the structure of the labour competencies of engineers based on the key skills of the professional activities inherent to a particular position, and determine the nature and content of the work as the object of assessing its impact on relevant indicators.

Keywords: employment competencies, work skills, key indicators of labour productivity, multitasking, interchangeability and specialization of labor.
} 
Исследование проблемы объективной оценки результатов труда инженеров конструкторских бюро и ее измерения по ключевым показателям эффективности, позволяют выдвинуть тезис о том, что данные показатели должны строится как на принципе их соответствия общим и индивидуальным трудовым функциям сотрудников, так и на принципе соответствия их содержаниясодержанию трудовых компетенций по конкретной должностной позиции. Иными словами, трудовые компетенции сотрудника должны определять потенциально возможный уровень его личностных и деловых качеств, необходимых для достижения высоких профессиональных результатов.Выдвинутый тезис о соответствии принципов построения показателей эффективности труда содержанию выполняемых трудовых функций и трудовых компетенций по выполняемой должности был проанализирован авторами в соответствующих публикациях, [1, 2, 3, 4].

В ходе реализации задачи построения системы ключевых показателей эффективности труда инженеров конструкторского бюро на одном из судостроительных предприятий Санкт - Петербурга, авторами были определены состав и структура основных трудовых компетенций применительно к различным должностям. В первую очередь, к таковым следует отнести:

- трудовые навыки, связанные с многозадачностью, т.е. с профессиональной способностью успешно решать задачи одновременно нескольких проектов, в т.ч. связанные с умением решать изобретательские задачи;

- трудовые навыки, связанные со способностью выполнять работы отсутствующего сотрудника, либо сотрудников со смежными специальностями.

Так, структура трудовых компетенций инженеров, определяющих уровень их профессионализма в условиях многозадачности, выглядит следующим образом (таблица 1).По - существу, весь перечисленный состав трудовых компетенций сотрудников определяется совокупностью их трудовых навыков и умением работать в условиях многозадачности. Чем выше квалификационный уровень инженера, тем больше навыков он обязан проявлять при одновременной работе сразу над несколькими проектами. 
Структура трудовых компетенцийинженеров конструкторского бюро Ключевой показатель эффективности труда: Многозадачность

\begin{tabular}{|c|c|c|c|c|c|c|c|}
\hline \multirow[b]{2}{*}{ Трудовыекомпетенции } & \multicolumn{7}{|c|}{ Должностные позиции сотрудников КБ } \\
\hline & 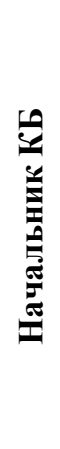 & 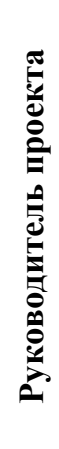 & 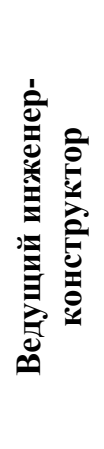 & 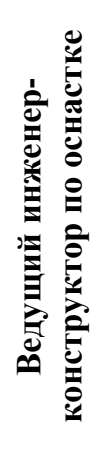 & 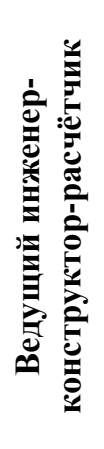 & 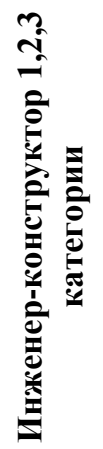 & 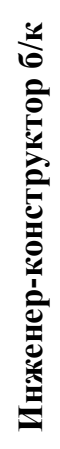 \\
\hline $\begin{array}{c}\text { Навык разработки, } \\
\text { оформления и } \\
\text { утверждения } \\
\text { конструкторской } \\
\text { документации. } \\
\end{array}$ & + & + & + & + & + & + & \\
\hline $\begin{array}{l}\text { Навык разработки, } \\
\text { оформления и } \\
\text { утверждения } \\
\text { технической } \\
\text { документации. }\end{array}$ & + & + & + & + & + & & \\
\hline $\begin{array}{c}\text { Умение составлять } \\
\text { техническое задание на } \\
\text { проект. }\end{array}$ & + & + & + & + & + & & \\
\hline $\begin{array}{c}\text { Знание типовых } \\
\text { технологических } \\
\text { процессов производства. }\end{array}$ & + & + & + & + & + & + & \\
\hline $\begin{array}{c}\text { Знание основных } \\
\text { материалов, } \\
\text { использующихя для } \\
\text { производства. }\end{array}$ & + & + & + & + & + & + & + \\
\hline $\begin{array}{c}\text { Уение решать } \\
\text { изобретательские } \\
\text { задачи. } \\
\end{array}$ & + & + & + & + & + & & \\
\hline
\end{tabular}

При этом возникает другая важная задача организации труда сотрудников конструкторского бюро: высокий уровень профессионализма инженера должен определяться не только навыками эффективной работы в условиях многозадачности, но и способностью к выполнению работы отсутствующего сотрудника. Это означает, что высококвалифицированный сотрудник обязан уметь выполнить эффективно не только свою работу, но и работу других сотрудников. Иными словами, специфика инженерного труда в условиях конструкторского бюро определяется наличием широкой специализации труда и возможностью его выполнения другими сотрудниками. Так, ведущий инженер должен уметь выполнить работу инженера 1 категории, а инженер 3 категории - 
работу техника - конструктора. Такая способность к взаимозаменяемости получила название «трудового универсализма», оценка уровня которого может производиться по соответствующему показателю (таблица 2).

Таблица 2

Структура трудовых компетенцийинженеров конструкторского бюро Ключевой показатель эффективности труда: Универсализм сотрудника

\begin{tabular}{|c|c|c|c|c|c|c|c|}
\hline \multirow[b]{2}{*}{ Трудовыекомпетенции } & \multicolumn{7}{|c|}{ Должностные позиции сотрудников КБ } \\
\hline & 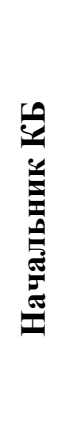 & 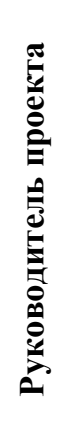 & 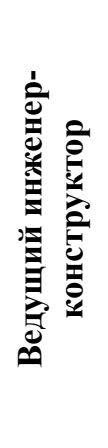 & 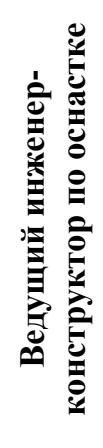 & 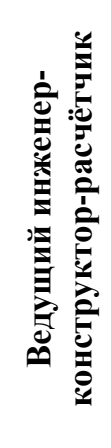 & 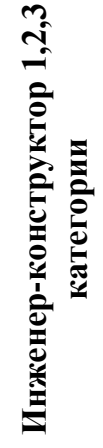 & 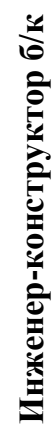 \\
\hline $\begin{array}{c}\text { Способность к выполнению } \\
\text { работы отсутствующего } \\
\text { сотрудника } \\
\end{array}$ & + & + & + & + & + & + & \\
\hline $\begin{array}{c}\text { Профессионализм и } \\
\text { разносторонняя подготовка }\end{array}$ & + & + & + & + & + & + & + \\
\hline $\begin{array}{c}\text { Стремление к обучению и } \\
\text { передаче профессионального } \\
\text { опыта } \\
\end{array}$ & & & + & + & + & + & + \\
\hline
\end{tabular}

В заключение необходимо отметить, что наиболее высокие результаты деятельности конструкторского бюро достигаются только при условии выполнения сотрудниками обоих ключевых показателей - многозадачности и универсализма. Правильный же выбор трудовых компетенций и ключевых трудовых навыков, отражающих характер и содержание труда по каждой должностной позиции, позволяет перейти к созданию системы мотивации инженерного труда по ключевым показателям эффективности на основе соответствующих критериев оценки профессиональных, личностных и деловых качеств. 


\section{Литература}

1. Давыдовский Ф.Н.Разработка системы премирования сотрудников центральных заводских лабораторий по ключевым показателям эффективности труда[Текст] // Аудит и финансовый анализ. 2014. № 5. C. 424-431.

2. Давыдовский Ф.Н.,Величко Е.А.Ключевые показатели эффективности труда и концепция построения премиальных систем сотрудников проектных команд [Электронный ресурс] //Системное управление. 2015. № 2 (27). C. 4.- Doi: 10.17686/sced_rusnauka_2015-1540

3. Давыдовский Ф.Н.,Величко Е.А.Методические вопросы апробации премиальных систем на предприятиях судостроительного комплекса города [Электронный ресурс]// Научный журнал НИУ ИТМО. Серия: Экономика и экологический менеджмент. 2015. № 3. C. 76-84. - Doi: 10.17686/sced_rusnauka_2015-1621

4. Давыдовский Ф.Н.,Величко Е.А.Принципы разработки системы ключевых показателей эффективности труда инженерно - технических работников машиностроительных предприятий[Текст]//Инновационная наука. 2016. № 5-1 (17). С. 38-40. 